concentration of electrolytes in $\mathrm{HeLa}$ cells provides a useful model for analysing the early events of mitosis and that changes in the biochemistry as well as morphology of such cells apparently hinge on the extent to which their chromatin is condensed. Perhaps Robbins and his colleagues will eventually achieve the ultimate goal--the induction of complete mitosis by manipulation of tonicity.

\section{SEISMOLOGY}

\section{Earthquake Swarms?}

from our Geomagnetism Correspondent

Some years ago, Mogi (Bull. Earthq. Res. Inst., 41, 615; 1963) found it convenient to distinguish between three types of earthquake sequence. The first comprised a clearly defined large shock accompanied by aftershocks; and the second was similar but with the addition of foreshocks. Mogi's third type was rather different, however, in that there was no large shock at all but only a closely spaced series of events of about the same size. This is the so-called earthquake swarm, a phenomenon which has received comparatively little attention.

The few studies carried out so far have been confined chiefly to continental swarms. And what has emerged from many of them is a clear association with volcanic eruption. Most of the swarms in Hawaii, for example, occur on the summit of Kilauea, an active volcano, and are associated with caldera collapse. So, too, was the large swarm which struck the Galapagos in June 1968. Swarms have also been identified with most of the major eruptions in the Lower Antilles and with volcanic activity in the central Pacific. Usually, however, swarm earthquakes are small. The Richter magnitude of an individual event within a swarm seldom exceeds 6 .

But volcanism occurs beneath the oceans as well as on land. Are there therefore any earthquake swarms associated with submarine volcanism ? Curiously, swarms originating from the mid-Atlantic ridge have been observed for more than ten years; but until now nobody has chosen to study them in detail or to understand their tectonic significance. Which is surprising, for earthquake swarms are, in fact, characteristic of the world rift system as a whole and are not the monopoly of the Atlantic ridge.

The correlation between oceanic ridges and earthquake activity is, of course, no longer a surprise in itself. But the earthquakes usually thought of in this connexion are individual events (Mogi's first and second types), mostly occurring along fracture zones (transform faults) and characterized by strike-slip faulting. From an analysis of more than twenty swarms from the mid-Atlantic ridge and the East Pacific Rise, however, Sykes (J. Geophys. Res., 75, 6598; 1970) has discovered that these swarms are restricted to the ridge crests and almost certainly possess large components of normal faulting. Occasionally they occur at intersections with fracture zones but never on the zones themselves. In other words, large earthquakes and earthquake swarms are associated with quite different tectonic features and thus presumably require quite different tectonic explanations.

Not surprisingly, because continental earthquake swarms are often associated with volcanism, Sykes is tempted to suggest that a similar association also applies to ridge swarms as well. Crustal zones of mid-oceanic ridges are, of course, known to be centres of sea floor spreading and the sources of submarine volcanism. But if the association is valid, does this mean that the mechanism for the production of earthquake swarms is physically related to volcanism ? Sykes freely admits that such a relationship is appealing; but points out that it cannot yet be proved. One of the characteristics of the earthquake swarm is its high $b$ value--the high percentage of smaller earthquakes-a feature produced by a concentrated stress source which could be, but is not necessarily, the result of volcanism. On the other hand, even the other obvious stress sources are closely related to volcanism. For example, heterogeneous materials and structures are likely to be situated in volcanic regions, and magmas and hydrothermal processes producing high fluid pressures are likely near volcanoes.

The case for the volcanic origin of

\title{
Cu(II)-Benzene Complex in Montmorillonite
}

MONTMORILlONITE, a silicate mineral with typical expanding layers, consists of mica-like sheets that are normally separated by one or two layers of water molecules. The water layers incorporate the exchangeable cations necessary to compensate the negative charge on the planar silicate anions; and polar organic molecules, such as acetone, pyridine, nitrobenzene, and many others, readily replace the interlayer water to give a variety of organic complexes. The organic molecules are either directly coordinated to the exchangeable cation, or held in outer spheres of coordination round hydrated cations by hydrogen bonds (V. C. Farmer, Clay Miner., 7, 373; 1968). Until now, interlayer adsorption of nonpolar organic molecules has been reported only where the exchangeable cation is itself organic.

Mortland and Pinnavaia show in next Monday's Nature Physical Science that benzene and other aromatic hydrocarbons will coordinate to exchangeable $\mathrm{Cu}(\mathrm{II})$ in montmorillonite under dry conditions. In one form of the complex the benzene structure is more profoundly modified than in any other benzene complex; no other complex between $\mathrm{Cu}$ (II) and benzene is known, although $\mathrm{Cu}(\mathrm{I})$ does form one. Participation of cuprous ion in the montmorillonite complex is excluded by electron spin resonance measurements.

Infrared spectroscopy shows that two forms of coordinated benzene can be present. In one, benzene vibrations are displaced only $10-20 \mathrm{~cm}^{-1}$ from those of the free molecule. Although these displacements are less than those generally found for typical sandwich complexes, such as $\mathrm{Cr}\left(\mathrm{C}_{6} \mathrm{H}_{6}\right)_{2}$, the interaction between $\mathrm{Cu}$ (II) and benzene is thought to be of this type. When this form alone is present, the complex is green. A dark red complex is formed by more rigorous dehydration, and is characterized by strong, broad absorption bands which are difficult to correlate with those of the free molecule. In addition to bands in the $1,550-1,800 \mathrm{~cm}^{-1}$ region, ascribed to $\mathrm{C}=\mathrm{C}, \mathrm{C}-\mathrm{C}$ and $\mathrm{C}-\mathrm{H}$ vibrations, an intense absorption extends from 1,700 $\mathrm{cm}^{-1}$ to beyond $4,000 \mathrm{~cm}^{-1}$, and is explained in terms of an electronic transition.

The change in infrared spectrum is so great that a new molecular species is suggested. An oxidative degradation would not be unexpected because adsorbed molecules readily oxidize on montmorillonite, and these reactions are promoted by transition metal cations (D. H. Solomon, B. C. Loft and J. D. Swift, Clay Miner., 7, 399; 1968). But this possibility is excluded for the Cu(II)benzene complex, because the red and green complexes are interconvertible by rehydration and dehydration, and only benzene is liberated when the complex is decomposed with acetone. A structure is proposed for the red complex in which $\mathrm{Cu}(\mathrm{II})$ is bonded to an edge of the ring, thus disrupting the aromatic resonance.

The role of the silicate layers in promoting the formation of the complexes is uncertain. Similar complexes are formed in hectorite in which the anion charge is widely distributed over the surface oxygens of the silicate layer, as in montmorillonite, so that the charge on any one oxygen is low. No complex is formed in expanding layer silicates in which the surface charge is concentrated on surface oxygens associated with $\mathrm{Al}^{3+}$ substituting for $\mathrm{Si}^{4+}$ in the silicate layers. It may be that the layer silicate minerals will yet prove as productive a hunting ground for chemists as have the zeolites. 